\title{
Potencial do endocarpo da manga (Mangifera indica L.) como adubo orgânico
}

A cultura da Mangifera indica L. possui ampla produção no nordeste e sudeste do Brasil, devido ao valor nutricional e propriedades do fruto. Entretanto, após o consumo in natura ou de manga processada, boa parte do fruto é desperdiçada, como o endocarpo. Com isso, o presente trabalho objetivou avaliar, qualitativamente, as características químicas do solo acrescido do adubo resultante da compostagem do endocarpo de manga, e o desenvolvimento longitudinal do milho (Zea mays L.) em vasos com diferentes substratos. A pesquisa foi realizada em Marabá/PA, e a metodologia empregada foi a observativa, sistemática e experimental. Foi realizada compostagem dos endocarpos de manga para a formação do Composto Orgânico Adicionado (COA), e a semeadura do milho foi feita para quatro tratamentos, com três repetições, em que os substratos utilizados foram: S1 - areia; S2 - terra preta; S3 - COA; S4 - COA + CNPK. Após o plantio foram efetuadas coletas de solo para análise química. Os dados obtidos indicaram que, na compostagem, somente temperatura não alcançou valores usualmente obtidos no processo, devido ao pequeno tamanho da leira no experimento. Quanto ao plantio, a temperatura esteve na faixa recomendável em todos os substratos, mas os maiores valores de umidade foram encontrados em S3 e S4. Em relação à análise química, houve incremento significativo dos macronutrientes, e isto levou ao maior desenvolvimento do milho em S3 e S4. Portanto, a adição de semente de manga à terra preta incrementou tal oferta, que, aliada à retenção hídrica, contribuiu para um melhor crescimento do milho.

Palavras-chave: Resíduos orgânicos; Incremento nutricional; Crescimento vegetativo.

\section{Potential of mango endocarp (Mangifera indica L.) as organic fertilizer}

\begin{abstract}
The Mangifera indica L. crop has extensive production in the northeast and southeast of Brazil, due to the nutritional value and properties of the fruit. However, after consumption in nature or processed mango, much of the fruit is wasted, such as the endocarp. With this, the present work aimed to evaluate, qualitatively, the chemical characteristics of the soil plus the fertilizer resulting from the composting of the mango endocarp, and the longitudinal development of corn (Zea mays L.) in pots with different substrates. The research was carried out in Marabá/PA, and the methodology used was observational, systematic and experimental. Mango endocarps were composted to form the Added Organic Compound (COA), and corn was sown for four treatments, with three replications, in which the substrates used were: S1 - sand; S2 - black earth; S3 - COA; S4 - COA + CNPK. After planting, soil samples were taken for chemical analysis. The data obtained indicated that, in composting, only temperature did not reach values usually obtained in the process, due to the small windrow size in the experiment. As for planting, the temperature was in the recommended range in all substrates, but the highest humidity values were found in S3 and S4. In relation to chemical analysis, there was a significant increase in macronutrients, and this led to the greater development of corn in S3 and S4. Therefore, the addition of mango seed to the black soil increased such supply, which, together with water retention, contributed to a better growth of corn.
\end{abstract}

Keywords: Organic waste; Nutritional increase; Vegetative growth

Topic: Desenvolvimento, Sustentabilidade e Meio Ambiente

Reviewed anonymously in the process of blind peer.

Emanoelen Bitencourt e Bitencourt Universidade do Estado do Pará, Brasil http://lattes.cnpq.br/4706004419015995 http://orcid.org/0000-0002-5560-6347 manuhbitencourt13@outlook.com

\section{Karina Miranda de Almeida (iD}

Universidade do Estado do Pará, Brasil http://lattes.cnpq.br/1768483891891553 http://orcid.org/0000-0002-0013-1604 karinamirandadealmeidakm@hotmail.com

Juliana Cardoso Ferreira (iD

Universidade do Estado do Pará, Brasil http://lattes.cnpq.br/6963533904473639

http://orcid.org/0000-0002-5176-7135 juuhferreira2199@gmail.com

d

DOI: 10.6008/CBPC2179-6858.2020.007.0048
Received: 04/12/2020

Approved: 21/12/2020

\author{
Gleidson Marques Pereira (iD \\ Universidade do Estado do Pará, Brasil \\ http://lattes.cnpq.br/4440253249173192 \\ http://orcid.org/0000-0003-0657-7356 \\ eng.gleidson.uepa@gmail.com

\section{Antonio Pereira Júnior} \\ Universidade do Estado do Pará, Brasil \\ http://lattes.cnpq.br/3239362677711162 \\ http://orcid.org/0000-0001-6241-985X \\ manuhbitencourt13@gmail.com
}

\section{Referencing this:}

BITENCOURT, E. B.; ALMEIDA, K. M.; FERREIRA, J. C.; PEREIRA, G. M.; PEREIRA JUNIOR, A.. Potencial do endocarpo da manga (Mangifera indica L.) como adubo orgânico. Revista Ibero Americana de Ciências Ambientais, v.11, n.7, p.619-629, 2020. DOI: 


\section{INTRODUÇÃO}

No Brasil, um dos frutos existentes é a manga (Mangifera indica L.), fruto bacáceo, de mesocarpo carnoso, monospérmico e climatérico, com endocarpo fibroso e, aroma e coloração característicos. A cultura teve boa adaptação no país quando foi introduzida pelos portugueses, no século XVII, e apesar de abundante na Amazônia, possui uma produção relevante nas regiões nordeste e sudeste, com áreas colhidas e quantidades produzidas de 49.549 ha e 784.692 t, e 19.701 ha e 334.881 t, respectivamente (AZÊREDO, 2013; IBGE, 2016; PINTO, 2008).

Em relação à composição química e o tamanho, esses diferem de acordo com a variedade da manga. Porém, de maneira geral, o endocarpo apresenta lipídios, proteínas, fibras e componentes fenólicos, contendo propriedades antioxidantes e antibactericidas. As propriedades químicas também dependem dos fatores climáticos, assim como o solo onde a mangueira se desenvolve (VIEIRA et al., 2009).

Quanto à semente, essa parte da manga é constituída principalmente de amido, o polissacarídeo de maior relevância nas células vegetais, visto que é a principal fonte de armazenamento de energia nas plantas. Este carboidrato é formado de amilose e amilopectina, ambas as estruturas formadas por unidades de glicose, e possuem moléculas enormemente hidratadas devido à presença de vários grupos hidroxila que realizam ligações de hidrogênio com a água (CORDEIRO, 2013).

Sobre o consumo, as mangas são muito consumidas in natura e também são processadas em indústrias alimentícias para a produção de polpas, geleias e outras variações. Nestes dois casos ocorre o descarte do endocarpo, em que somente na amêndoa encontra-se o aproximado de $77 \%$ de carboidratos, 11\% de lipídeos, $6 \%$ de proteínas, $2 \%$ de fibras e $2 \%$ de cinzas (MENDES et al., 2012).

Nessa perspectiva, o processamento da manga apresenta um desperdício de $40-50 \%$ da massa total da fruta, e essas porções podem ser utilizadas como uma opção de fonte de nutrientes. Então, o aproveitamento desses materiais orgânicos é de grande relevância, visto que é importante ao setor econômico, pois se trata de uma fruta sazonal e abundante em países tropicais. Entretanto, o aproveitamento deve ser feito com o intuito de preservar o valor nutricional (DAMIANI et al., 2011).

Outro fator são os resíduos gerados pós-consumo. Uma maneira de aproveitá-los é a aplicação deles na compostagem, uma técnica de oxidação biológica em que os microrganismos decompõem os compostos constituintes dos materiais orgânicos, e transformam os resíduos em substâncias húmicas. Esse processo resulta na liberação de dióxido de carbono $\left(\mathrm{CO}_{2}\right)$ e vapor de água, e também é mencionado como um processo biológico de decomposição aeróbia e anaeróbia, realizada quase na totalidade por processos aeróbios (OLIVEIRA et al., 2008).

Esse procedimento é feito pela combinação de resíduos orgânicos, de preferência ricos em carbono (C) e nitrogênio (N), como restos de frutos e vegetais, e o resultado é um adubo orgânico homogêneo, escuro, estável e solto. Logo, ele pode ser utilizado em qualquer cultura, sem riscos de dano, e com capacidade de proporcionar melhoramento nas propriedades físico-químicas e biológicas do solo, seja pela facilitação de nutrientes às plantas, retenção de umidade, efeito tampão ou maior porosidade. Ademais, o processo é de 
baixo custo (DOETZER, 2009; WANGEN et al., 2010).

Devido à abundância do fruto, desperdício e à parca quantidade de informações acerca do uso do endocarpo da manga (Mangifera indica L.) como complemento nutricional do solo, o objetivo dessa pesquisa foi avaliar, qualitativamente, as características químicas do solo acrescido do adubo resultante da compostagem do endocarpo de manga, e o desenvolvimento longitudinal do milho (Zea mays L.) em vasos com diferentes substratos, incluindo o acrescido do endocarpo de manga.

\section{MATERIAIS E MÉTODOS}

O experimento foi realizado no Campus VIII da Universidade do Estado do Pará, no município de Marabá - PA, a 580 km da capital Belém (MARABÁ, 2017). O clima e solo predominantes no município são o tropical semiúmido e Argissolo Vermelho Amarelo, respectivamente (GREGO et al., 2015). A hidrologia é constituída pelos rios Itacaiúnas e Tocantins (CÂMARA, 2012). E a vegetação mais representativa são Florestas (Terra Firme, Inundada, Secundária e com Babaçu) e o Pasto (AFFONSO et al., 2005).

A metodologia utilizada foi a observativa, sistemática, com pesquisa experimental, ou seja, parte-se da seleção de variáveis, com o objeto de estudo definido, para determinar as formas de controle da ação dessas variáveis sobre o objeto estudado (GIL, 2008). Para melhor aplicação dessa metodologia, dividiu-se a mesma, em cinco etapas (Figura 1).

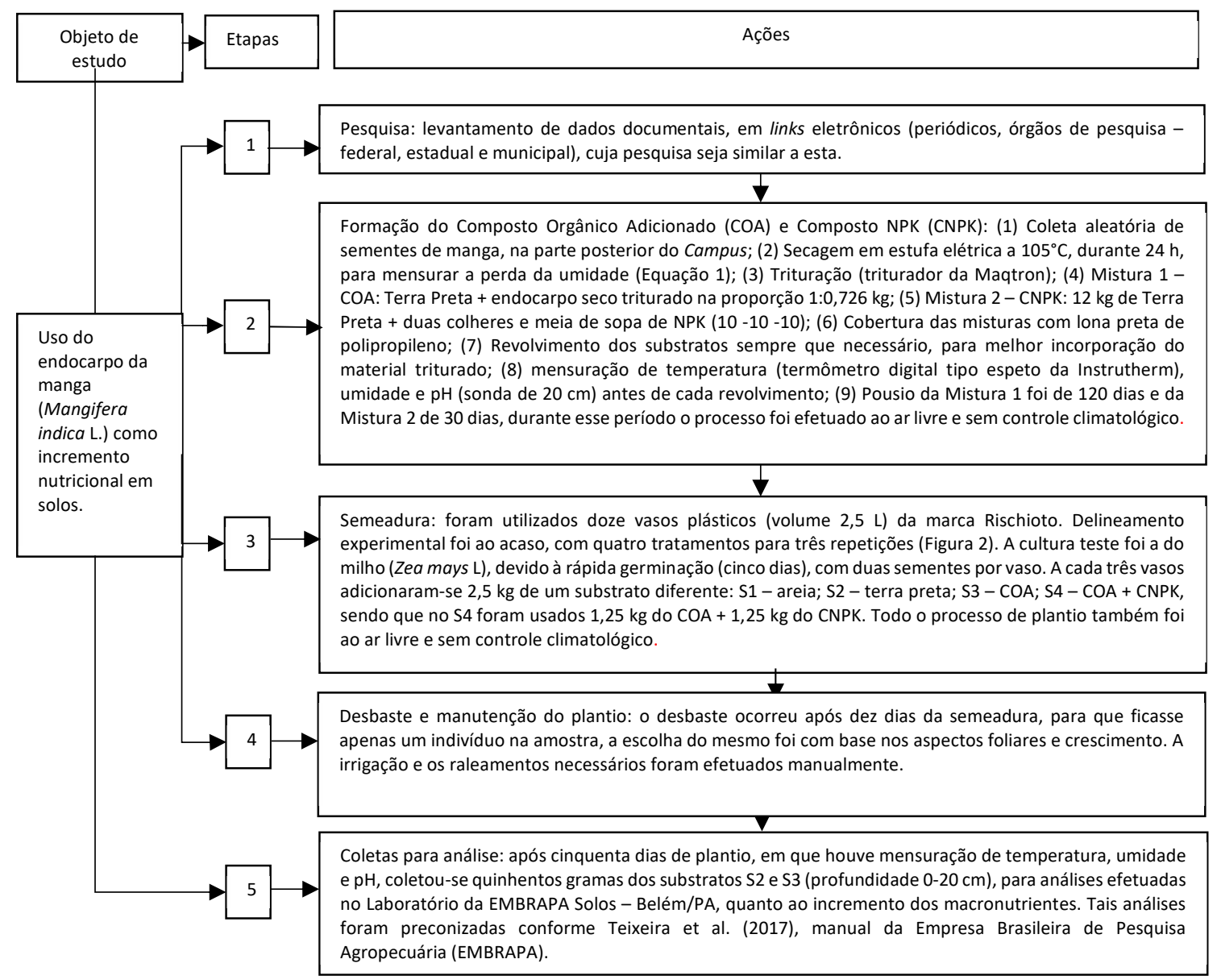

Figura 1: Fluxograma das etapas de aplicação da metodologia.

$$
P L=P U-P S
$$


Onde: PL - Peso líquido; PU - Peso Úmido; PS - Peso Seco.

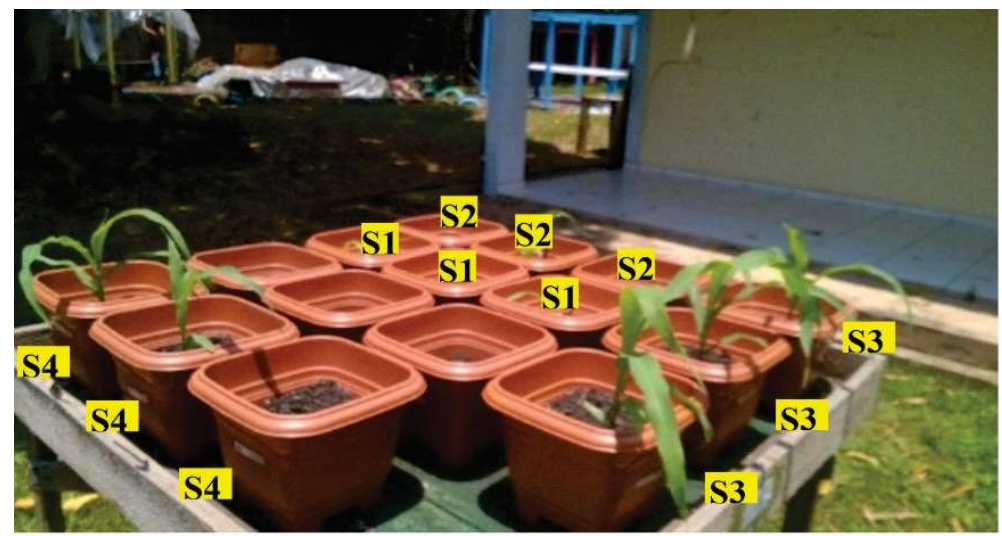

Figura 2: Vista superior da disposição dos vasos com os substratos (S1, S2, S3, S4), no pallet. Marabá/PA

\section{RESULTADOS E DISCUSSÃO}

\section{Quanto à perda de umidade no material}

A análise dos dados obtidos, após $24 \mathrm{~h}$ de secagem dos endocarpos, indicou que a massa total $(15,750$ $\mathrm{kg}$ ), foi reduzida para 7,620 kg. Logo, houve perda de umidade de 8,13 $\mathrm{kg}$ (Tabela 1), o que corresponde a $51,61 \%$ da massa total coletada.

Tabela 1: Dados da mensuração de massa úmida, seca e triturada. Marabá/PA.

\begin{tabular}{lllll}
\hline & Mti & Mtf & Perdas & \\
\cline { 2 - 5 } & $\mathrm{kg}$ & $\mathrm{kg}$ & $\mathrm{kg}$ & $\%$ \\
\cline { 2 - 5 } Umidade & 15,750 & 7,620 & 8,13 & 51,61 \\
Trituração & 7,620 & 4,358 & 3,262 & 42,80 \\
\hline
\end{tabular}

Mti - massa total inicial (coletada); Mtf - massa total final (após a secagem e a trituração).

Pesquisa efetuada em Porto Alegre - RS, por Bard (2011), indicou que, a temperatura influencia bastante na cinética de secagem. Na pesquisa realizada em Marabá, à medida que o calor foi transferido do meio para o endocarpo a massa foi transferida do endocarpo para o meio, o que levou ao encolhimento do endocarpo, dados que corroboram com a afirmativa de Bard.

Outro estudo realizado em Campina Grande - PB, por Santos (2015), concluiu que, por meio da secagem de $1 \mathrm{~g}$ de amido em estufa por $2 \mathrm{~h}$ a $105^{\circ} \mathrm{C}$, a perda de umidade do amido extraído da amêndoa do endocarpo foi de $9,23 \% \pm 0,271$ em mangas da variedade Tommy Atkins.

No tocante à trituração, feita depois da secagem, ela levou à redução da área individual das amêndoas, em que o peso obtido do farináceo equivaleu a 4,358 kg, ou seja, uma redução na massa seca equivalente a 42,80\%. Em pesquisa realizada em Fortaleza - CE, por Silva et al. (2016), os autores indicaram que a farinha resultante da trituração dos caroços de manga da variedade Ubá tem composição centesimal (umidade, proteínas, lipídeos, cinzas e carboidratos) variável em função do cultivar, fatores climáticos e ambientais em que o fruto é exposto, e estes fatores influenciam no teor de amido das amêndoas.

\section{Quanto aos dados da compostagem para formação do COA}

Os dados obtidos, após oito revolvimentos consecutivos do Composto Orgânico Adicionado (COA), indicaram uma boa desenvoltura deste ao longo do processo. Tal afirmativa foi efetuada após a análise dos 
dados de temperatura, umidade e potencial Hidrogeniônico - pH do solo (Figura 3).

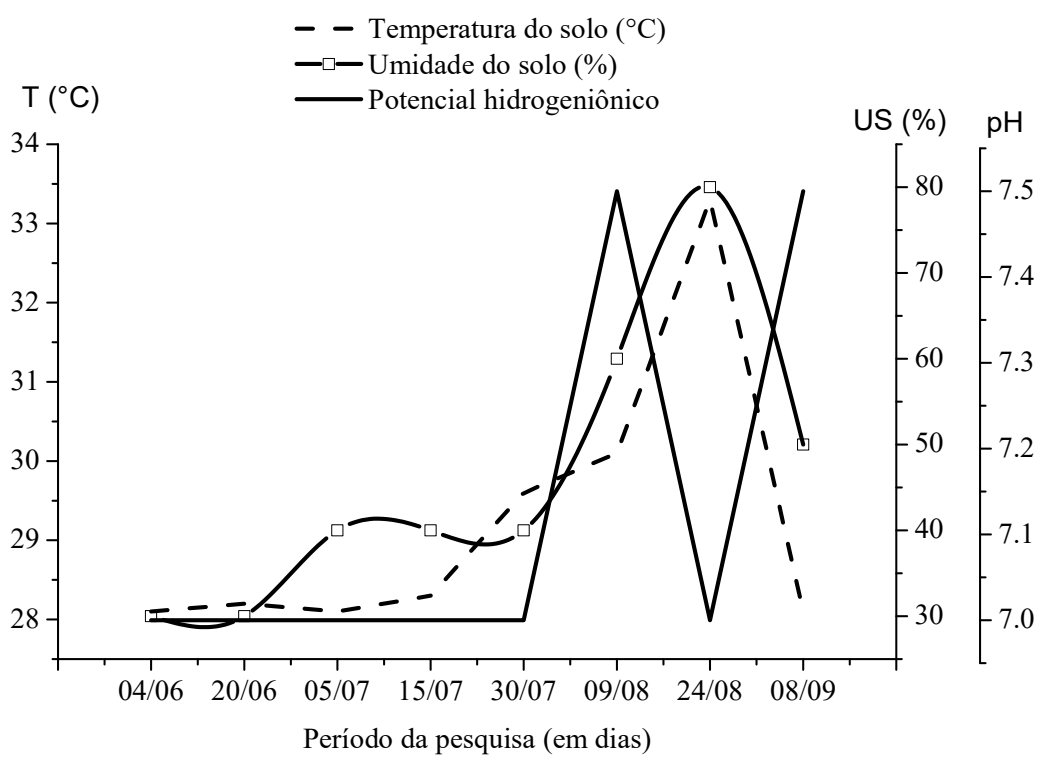

Figura 3: Variáveis mensuradas durante a compostagem. Marabá/PA.

T: temperatura do solo; US: umidade do solo; pH: potencial Hidrogeniônico.

O processo de evolução da compostagem pode ser avaliado por três variáveis: temperatura, umidade e pH do solo. Sobre a temperatura, houve uma tendência de elevação $\left(28,1^{\circ} \mathrm{C}\right.$ a $\left.33,3^{\circ} \mathrm{C}\right)$. Valente et al. (2009) e Pereira (2013), afirmam que na fase inicial de decomposição, fase mesófila, prevalecem bactérias, que na fragmentação inicial de matéria emancipam calor no meio, o que causa a morte dos microrganismos mesófilos, com a sucessiva proliferação de organismos termófilos.

Em Marabá, a elevação de temperatura não ocorreu no início, mas a partir de 15/07, depois de 30 dias do início do processo, e mesmo assim não atingiu mais de 35 ำ , talvez pela pequena altura da leira (15 $\mathrm{cm})$, já que não foi utilizada grande quantidade de substrato.

Quanto à umidade do composto, está apresentou tendências similares aquelas da temperatura. Ela sofreu elevação (máxima de $80 \%$ ) durante a fase termófila, após esse período, ela foi reduzida (50\%). Estudo realizado em Poços de Caldas - MG, por Demetrio et al. (2016) concluíram que o teor de umidade ideal deve estar entre $50 \%$ (valor final de umidade encontrada pelos autores) e 60\%, e ainda afirmaram a questão desta faixa ótima ser favorável para a atividade microbiana e a decomposição. O percentual mensurado em Marabá (50\%) apresenta-se inserido na faixa da umidade ótima.

Em relação ao pH, este apresentou tendência a se manter constante $(7,0)$, ou seja, neutralidade. De acordo com Cotta et al. (2015), a geração de dióxido de carbono $\left(\mathrm{CO}_{2}\right)$, atrelada aos ácidos orgânicos originários das ações dos microrganismos, possuem relação com o pH, e isto pode levar a pequenas variações deste no sistema tampão do solo, o que também pode ocorrer mediante bases. Quanto as estreitas variações no $\mathrm{pH}$, isso ocorreu no experimento realizado em Marabá $(0,1$ a 0,5). A basicidade observada pode ter origem na farinha do endocarpo da manga, pois houve aumento da saturação de bases.

Em pesquisa efetuada no município de Pombal - PB, por Pedrosa et al. (2013), os autores indicaram que o valor final do $\mathrm{pH}$ de determinado composto varia de acordo com a origem do mesmo, e altos valores de $\mathrm{pH}$ podem estar ligados à uma grande quantidade de nitrogênio disponível. Este incremento de nitrogênio 
foi verificado em Marabá, e o composto orgânico, que tendeu à neutralidade, ficou em uma faixa ótima para o desenvolvimento de microrganismos.

\section{Quanto às variáveis mensuradas durante o plantio}

No que tange à temperatura, os dados obtidos indicaram que, em S3, a tendência da temperatura média foi para diminuição quando comparada com S1 e S2, e para equilíbrio quando comparado com S4. Para a umidade média do COA em S3, os dados indicaram um maior percentual $(51,69 \%)$ em relação a S1, S2 e S4. E, quanto ao pH, os dados indicaram uma tendência a neutralidade 7,1, a 7,5 (Figura 4).

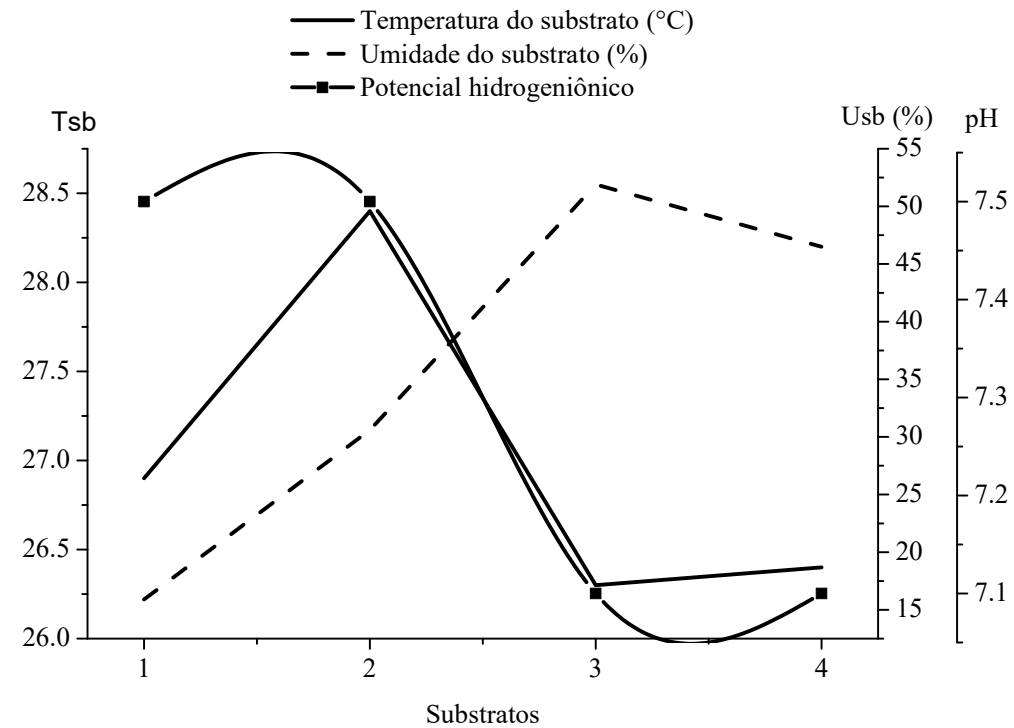

Figura 4: Variáveis mensuradas durante o plantio. Marabá/PA. Tsb: Temperatura do substrato; Usb: Umidade do substrato; $\mathrm{pH}$ : potencial Hidrogeniônico; 1: areia; 2: terra preta; 3: COA; 4: COA + NPK.

Em estudo efetuado no município de Curitibanos - SC, por Ribeiro (2016), o autor concluiu que, uma temperatura superior a $16^{\circ} \mathrm{C}$ aliada a uma considerável umidade, possibilita não só uma boa germinação do milho, como também uma eficiente desenvoltura do mesmo. E em pesquisa realizada em Botucatu - SP, por Santana (2012), indicou que, para o crescimento desta cultura, a faixa ideal é de 25 드 a $30 \circ \mathrm{C}$. Em Marabá, todos os substratos estiveram na faixa recomendável, mas os maiores valores de umidade foram verificados em S3 e S4, os quais apresentaram maior desenvolvimento perante os demais substratos.

No que diz respeito à retenção hídrica, em estudo efetuado em Fernandópolis - SP, por Silva et al. (2012), concluíram que, os teores de água no solo influenciaram no desenvolvimento da cultura, como crescimento e produtividade. Já os autores Kunz et al. (2007), em estudo efetuado em Brasília - DF, concluíram que o crescimento da planta está associado ao melhor uso da radiação fotossinteticamente ativa, o que resultou na eficiente retenção. No experimento realizado em Marabá, a retenção hídrica mostrou influência no desenvolvimento da cultura, corroborando com os autores.

Com relação ao pH mensurado durante o cultivo, houve tendência à neutralidade. Pesquisa efetuada em Veranópolis - RS, por Rodrigues et al. (2009), indicaram que o pH aconselhado para a cultura de milho varia entre 5,5 e 6,0. Em Marabá, a cultura se desenvolveu melhor nos substratos S3 e S4, ambos com valor médio de $\mathrm{pH}$ de maior neutralidade $(7,1)$. 


\section{Quanto à análise química em S2 e S3}

Em relação às análises químicas dos substratos S2 e S3, a análise dos dados obtidos indicou que, em S3, os teores dos macronutrientes (primários e secundários) foram elevados quando comparados com S2 (Tabela 2).

Tabela 2: Análise química em S2 e S3. Marabá/PA.

\begin{tabular}{|c|c|c|c|c|c|c|c|c|}
\hline$a$ & C & MO & $\mathbf{N}$ & $C / N$ & $\mathrm{pH}$ & $\mathbf{P}$ & $\mathbf{K}$ & $\mathrm{Na}$ \\
\hline Unidade & \multicolumn{4}{|c|}{----------g/kg--------- } & água & \multicolumn{3}{|c|}{--------mg/dm³------- } \\
\hline $\mathrm{S} 2$ & 51,72 & 89,22 & 1,12 & 46,05 & 6,3 & 19 & 826 & 41 \\
\hline S3 & 62,32 & 107,5 & 4,47 & 13,94 & 7,8 & 34 & 1049 & 39 \\
\hline b & $\mathrm{Ca}$ & $\mathrm{Ca}+\mathrm{Mg}$ & Al & $\mathrm{H}+\mathrm{Al}$ & CTCt & CTCef & SATb & SATal \\
\hline Unidade & \multicolumn{4}{|c|}{-----------cmolc/dm³-------- } & cmolc & & V\% & $\mathrm{m} \%$ \\
\hline S2 & 8,2 & 10,7 & 0 & 6,93 & 19,93 & 13 & 65,22 & 0 \\
\hline S3 & 2,4 & 12,8 & 0 & 1,32 & 16,98 & 15,66 & 92,22 & 0 \\
\hline
\end{tabular}

S: Substrato; C: Carbono; MO: Matéria Orgânica; N: Nitrogênio; pH: potencial Hidrogeniônico; P: Fósforo; K: Potássio; Na: Sódio; Ca: Cálcio; Mg: Magnésio; Al: Alumínio; H: Hidrogênio; CTCt: Capacidade de Troca Catiônica total; CTCef: Capacidade de Troca Catiônica efetiva; SATb: Saturação de bases; SATal: Saturação de alumínio.

Estudo realizado em Fortaleza - CE, por Rodrigues et al. (2011), concluíram que houve acréscimo nos teores de C, N, P, K, Ca, e Mg, no solo, por conta da adubação com composto orgânico, o que reflete no enriquecimento nutricional do composto. Em Marabá, após a inserção do farináceo do endocarpo à Terra Preta (S3), houve indicação no incremento nutricional desse substrato, o que pode ser comprovado a partir dos teores de C, N, P, K e Ca+Mg, corroborando com a afirmativa de Rodrigues et al.

O acúmulo de Nitrogênio (N), após a compostagem, pode estar associado ao desenvolvimento da cultura no substrato S3, onde visualmente, ocorreram os maiores cultivos, seguidos de S4 (Figura 5).

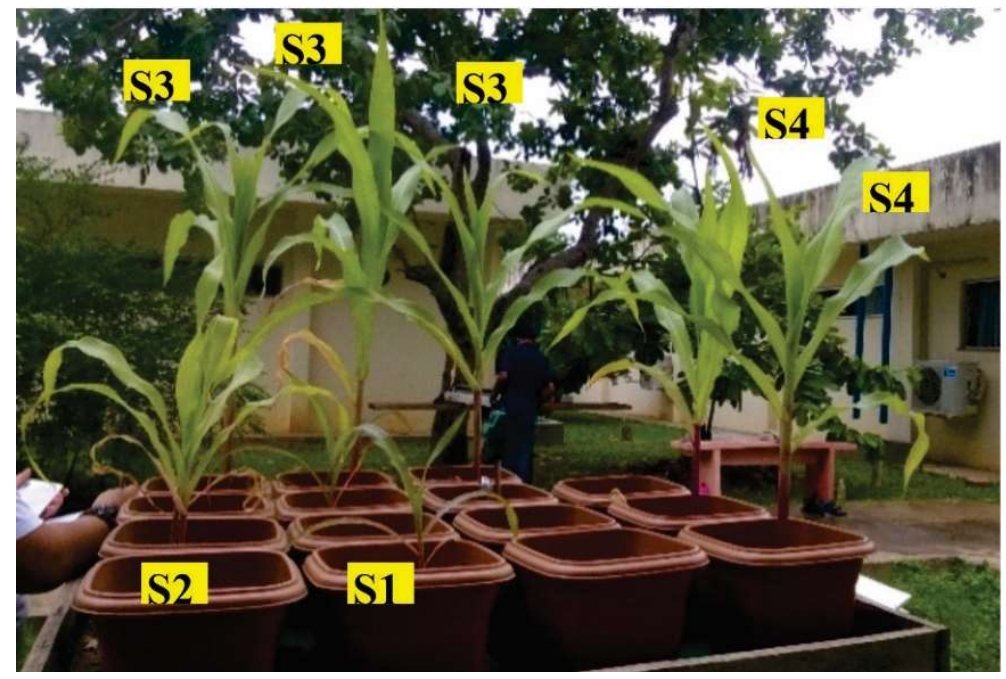

Figura 5: Desenvolvimento da cultura em S3 e S4. Marabá/PA.

Pesquisa efetuada em Marechal Cândido Rondon - PR, por Dartora et al. (2013), indicaram que esse elemento é de grande importância tanto na produção de folhas, pois está presente na célula vegetal, quanto no aumento da produtividade e crescimento do mesmo. Na pesquisa efetuada em Marabá, o teor de nitrogênio no composto orgânico S3 elevou-se, por isso, o milho desenvolveu-se tanto em tamanho e número de folhas quando comparado com S2, que corrobora com a afirmativa de Dartora et al.

Quanto aos macronutrientes N e K, os dados obtidos indicaram que o K também apresentou maior 
teor em S3. No estudo realizado em Santa Maria - RS, por Silva et al. (2011), concluíram que o N está atrelado ao $\mathrm{K}$, e a interação destes influencia na atividade da enzima nitrato redutase, e consequentemente no metabolismo do N. No estudo realizado em Marabá, o acréscimo no teor de K auxiliou no metabolismo de N, portanto influenciou também no desenvolvimento da cultura em S3.

Em relação à $\mathrm{MO}$ e a CTC efetiva, a análise dos dados indicou que os teores em S3 foram elevados em relação a S2, corresponderam a uma diferença de $18,28 \mathrm{~g} / \mathrm{kg}$ e $2,66 \mathrm{cmolc} / \mathrm{dm}^{3}$, respectivamente. A pesquisa efetuada em Campinas - SP, por Ronquim (2010), indicou que os teores elevados de MO e de CTC efetiva nos solos de regiões tropicais provoca elevação na capacidade de tamponamento do solo e isso beneficia o cultivo. Os dados obtidos em Marabá indicaram valores elevados para a CTC, e isso favoreceu o crescimento do milho.

\section{Quanto ao desenvolvimento da espécie}

Em relação a S3 e S4, a análise dos dados obtidos indicou que houve maior desenvolvimento, especialmente em S3, do meristema apical e melhor proliferação foliar nos indivíduos ali semeados, assim como maior diâmetro caulinar, do início (Figura 6) ao fim da plantação (Figura 7), sendo que somente em S3 houve germinação em todos os vasos. Além disso, ao final do experimento verificaram-se ainda, em S3 e S4 maiores desenvolvimentos radiculares (Figura 8).

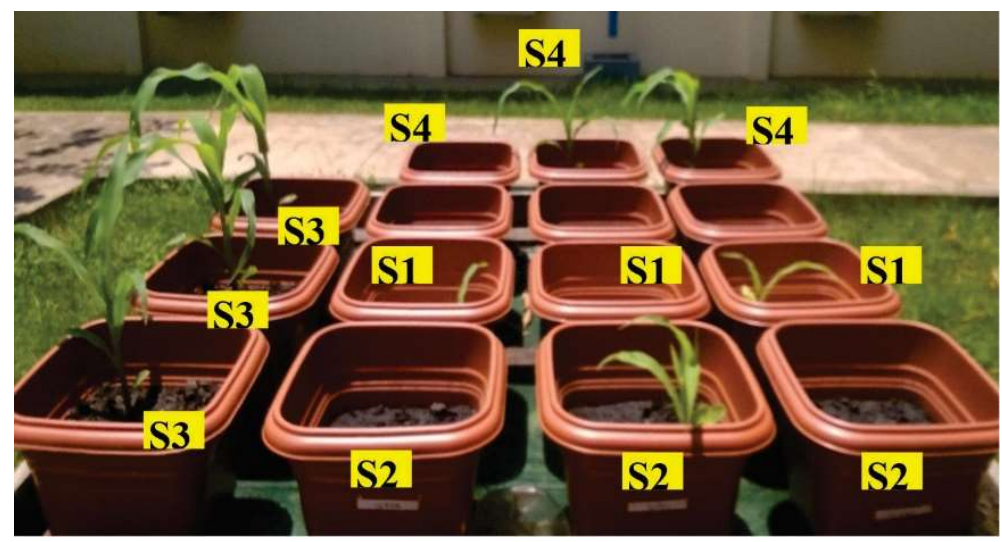

Figura 6: Desenvolvimento inicial da cultura. Marabá/PA.

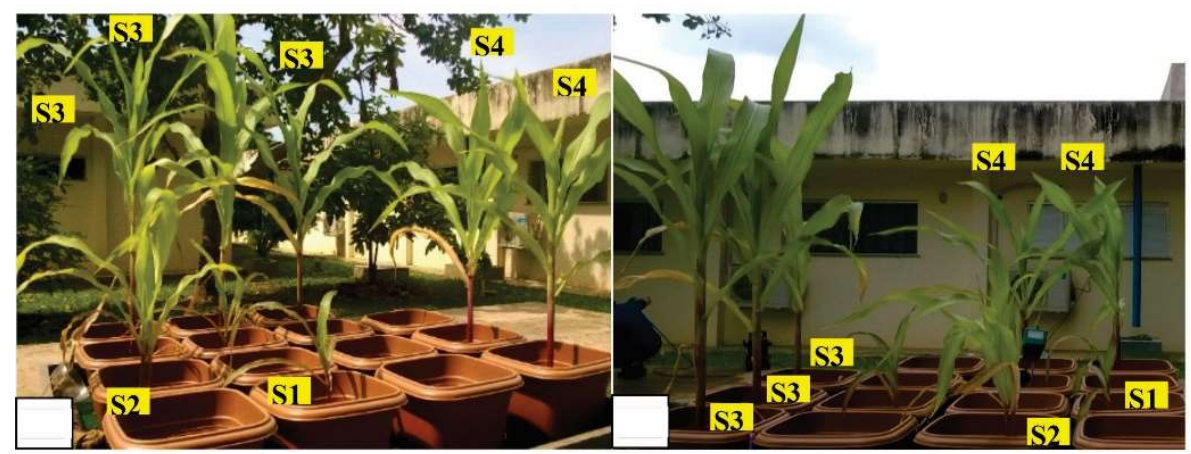

Figura 7: Desenvolvimento final da cultura com: a) Vista lateral direita de S4; b) Vista lateral esquerda de S3. Marabá/PA. 


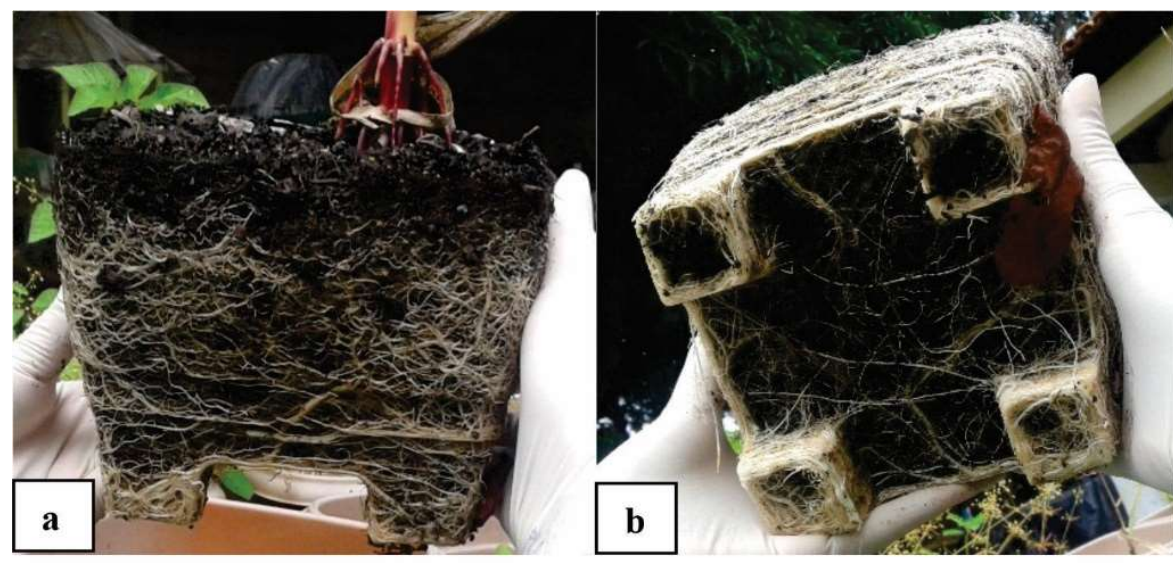

Figura 8: Desenvolvimento do sistema radicular com: a) Vista lateral do sistema radicular em S3 e 4; b) Vista inferior do sistema radicular em S3 e S4.

Em S3, o desenvolvimento pode ser explicado pela análise química ou mesmo pela estrutura do solo após a compostagem. Em estudo efetuado em São Carlos - SP, por Dores-Silva et al. (2013), concluíram o efetivo melhoramento das características físico-químicas das matrizes, como o elevado grau de humificação e CTC efetiva, após o processo de estabilização de compostos orgânicos por meio da compostagem.

Já em S4, o segundo maior desenvolvimento observado, além do COA, continha NPK. Em pesquisa realizada em Botucatu - SP, por Santana (2012), indicou que a aplicação de fertilizante organomineral não proporcionou efeito expressivo sobre o comprimento, diâmetro, altura de inserção da espiga e rendimento de grãos para a cultura do milho, assim como não houve interação para a densidade, e micro e macroporosidade. Em Marabá, houve similaridade entre os desenvolvimentos em S3 e S4, corroborando com os resultados de Santana. Com relação a S2, em estudo efetuado no município de Manacapuru - AM, por Klüppel (2006), concluiu que as Terras Pretas de Índio (TPI) são utilizadas para as plantações de espécies de ciclo curto, além de possuírem alta fertilidade, $\mathrm{com} \mathrm{pH}_{(\mathrm{H} 2 \mathrm{O})}$ em torno de 6, e elevado teor de Cálcio, Fósforo e matéria orgânica. Por conta dessas características o milho é uma espécie bem adaptada às TPI, as quais proporcionam o bom desenvolvimento da cultura.

Assim como na pesquisa realizada em Iranduba - AM, por Gonçalves et al. (2009), em que os autores indicaram elevadas concentrações de Magnésio, Zinco, Manganês e Cobre atrelados a alta Capacidade de Troca Catiônica e saturação por bases nas TPI, e o milho também desenvolveu bem nessas condições. Entretanto, no estudo realizado em Marabá a cultura teve baixo desenvolvimento, o que pode estar conexo às características físicas do solo.

Em estudo efetuado nos municípios de Melgaço e Igarapé-Açu - PA, por Barros et al. (2016), concluíram que há variação granulométrica entre os horizontes dos solos de Terra Preta Arqueológica (TPA), também conhecida como TPI, e isso torna difícil a caracterização física destes. Todavia, concluíram que a maior influência nas propriedades físicas, como o espaço poroso, está conectada ao teor de matéria orgânica (inferior ao S3 - Tabela 2). Sobre esse espaço poroso, ainda segundo os mesmos autores, os poros do tipo estrutural e textural são essenciais ao desenvolvimento da cultura, pois proporcionam abrigo de organismos vivos (decompõem e ciclam material orgânico), melhoria na aeração das raízes, condução e drenagem da água; e aumento na retenção e disponibilidade de água às plantas. Afirmação semelhante foi feita por Klein 
et al. (2010), em que os autores indicaram também a influência da argila no teor de água no solo. Em Marabá, o desenvolvimento reduzido em S1 e S2 pode ser explicado por esses fatores.

\section{CONCLUSÕES}

O crescimento caulinar e radicular de cultivos depende da qualidade e da oferta de macro e micronutrientes contidos no substrato. A adição de farináceo da semente de Mangifera sp. à Terra Preta, incrementou tal oferta e contribuiu para um melhor desempenho no crescimento do milho.

Esta associação melhorou a retenção da umidade, o que proporcionou melhor mineralização da matéria orgânica e, consequentemente, distribuição de macronutrientes essenciais ao crescimento de caule e folhas da espécie estudada. Para uma aplicação dessa técnica em alta escala, outros estudos, na mesma proporção, deverão ser efetivados.

\section{REFERÊNCIAS}

AFFONSO, A. G.; VALERIANO, D. M.; BATISTA, G. T.. Caracterização da vegetação no município de Marabá, no estado do Pará, através de dados e transformações espectrais (Índice de Vegetação por Diferença Normalizada) do sensor ETM+ / Landsat 7. In: SIMPÓSIO BRASILEIRO DE SENSORIAMENTO REMOTO, 12. Anais. Goiânia: INPE, 2005.

AZÊREDO, L. P. M.. Qualidade de mangas 'Tommy Atkins' da produção integrada sob recobrimento biodegradável associados a óleos essenciais de erva-doce e orégano. Dissertação (Mestrado em Ciência e Tecnologia de Alimentos) - Universidade Federal da Paraíba, João Pessoa, 2013.

BARD, E. K.. Estudo da secagem convectiva da casca de manga visando minimizar a perda de compostos fenólicos. Monografia (Bacharelado em Engenharia Química) Universidade Federal do Rio Grande do Sul, Porto Alegre, 2011.

BARROS, K. R. M.; LIMA, H. V.; RODRIGUES, S.; KERN, D. C.. Distribuição da porosidade textural e estrutural em solos de Terra Preta Arqueológica. Revista Ciência Agronômica, Fortaleza, v.47, n.4, p.609-615, 2016. DOI: http://doi.org/10.5935/1806-6690.20160073

CÂMARA, R. K. C.. Previsão estocástica de nível fluviométrico para cidade de Marabá/PA: Método de Box \& Jenkins. Dissertação (Mestrado em Ciências Ambientais) Universidade Federal do Pará, Belém, 2012.

CORDEIRO, E. M. S.. Biocompósitos poliméricos obtidos a partir da fração lignocelulósica e amilácea do caroço de manga (Mangifera indica), Tommy Atkins. Dissertação (Mestrado em Ciência e Engenharia dos Materiais) Universidade Federal do Rio Grande do Norte, Natal, 2013.

COTTA, J. A. O.; CARVALHO, N. L. C.; BRUM, T. S.; REZENDE, M. O. O.. Compostagem versus vermicompostagem: comparação das técnicas utilizando resíduos vegetais, esterco bovino e serragem. Engenharia Sanitária e Ambiental, Rio de Janeiro, v.20, n.1, p.65-78, 2015. DOI: http://doi.org/10.1590/S1413-41522015020000111864

DAMIANI, C.; ALMEIDA, A. C. S.; FERREIRA, J.; ASQUIERI, E. R.; BOAS, E. V. B. V.; SILVA, F. A.. Doces de corte formulados com casca de manga. Pesquisa Agropecuária Tropical, Goiânia, v.41, n.3, p.360-369, 2011. DOI: http://doi.org/10.5216/pat.v41i3.9815
DARTORA, J.; GUIMARAES, V. F.; MARINI, D.; SANDER, G.. Adubação nitrogenada associada à inoculação com Azospirillum brasilense e Herbaspirillum seropedicae na cultura do milho. Revista Brasileira de Engenharia Agrícola e Ambiental, v.17, n.10, p.1023-1029, 2013. DOI: http://doi.org/10.1590/S1415-43662013001000001

DEMETRIO, L. F. F.; NAKAGAWA, D. H.; PINTO, A. A. S.; PRESUMIDO, P. H.; BERTOZZI, J.; MICHELS, R. N.; BOSCO, T. C. D.; PRATES, K. V. M. C.. Compostagem em pequena escala de resíduos sólidos de restaurante universitário associado a poda de árvores. In: CONGRESSO NACIONAL DE MEIO AMBIENTE, 13. Anais. Poços de Caldas: IFSULDEMINAS, 2016.

DOETZER, B. H. W.. Aproveitamento de resíduos orgânicos de grandes geradores na produção agropecuária e reciclagem agrícola na região metropolitana de Curitiba. In: CONGRESSO BRASILEIRO DE RESÍDUOS ORGÂNICOS, 1. Anais. Vitória: INCAPER, 2009.

DORES-SILVA, P. R.; LANDGRAF, M. D.; REZENDE, M. O. O.. Processo de estabilização de resíduos orgânicos: Vermicompostagem versus Compostagem. Química Nova, São Paulo, v.36, n.5, p.640-645, 2013. DOI: http://doi.org/10.1590/S0100-40422013000500005

GIL, R. L.. Tipos de Pesquisa. 2008.

GONÇALVES, J. R. P.; FONTES, J. R. A.; DIAS, M. C.; DIÓGENES, H. C.. Fertilidade de um Argissolo com Horizonte A Antrópico (Terra Preta de Índio) e produtividade de milho em Iranduba/AM. In: CONGRESSO BRASILEIRO DE CIÊNCIA DO SOLO, 32. Fortaleza. Anais. Fortaleza: UFC, 2009.

GREGO, C. R.; GALDINO, S.; BOLFE, É. L.; NOGUEIRA, S. F.; BAYMA-SILVA, G.; ARAUJO, L. S.; POCCARD-CHAPUIS, R.; THALÊS, M. C.. Distribuição espacial das classes de degradação de pastagem em Marabá, PA e sua correlação com as classes de solo e relevo. In: SIMPÓSIO BRASILEIRO DE SENSORIAMENTO REMOTO, 17. Anais. João Pessoa: INPE, 2015.

IBGE. Instituto Brasileiro de Geografia e Estatística. Produção Agrícola Municipal. Rio de Janeiro: IBGE, 2013.

KLEIN, V. A.; BASEGGIO, M.; MADALOSSO, T.; MARCOLIN, C. D.. Textura do solo e a estimativa do teor de água no ponto 
de murcha permanente com psicrômetro. Ciência Rural, v.40, n.7, p.1550-1556, 2010. DOI: http://doi.org/10.1590/S0103-84782010005000110

KLÜPPEL, M. P.. Sistemas agrícolas e plantas medicinais em Terras Pretas de Índio da Amazônia Central. Dissertação (Mestrado em Ciências Agrárias) - Universidade Federal do Amazonas, Manaus, 2006.

KUNZ, J. H.; BERGONCI, J. I.; BERGAMASCHI, H.; DALMAGO, G. A.; HECKLER, B. M. M.; COMIRAN, F.. Uso da radiação solar pelo milho sob diferentes preparos do solo, espaçamento e disponibilidade hídrica. Pesquisa Agropecuária Brasileira, Brasília, v.42, n.11, p.1511-1520, 2007. DOI: http://doi.org/10.1590/S0100204X2007001100001

MARABÁ. Prefeitura de Marabá. A cidade. Marabá: DOE, 2017.

MENDES, M. L. M.; BORA, P. S.; RIBEIRO, A. P. L.. Propriedades morfológicas e funcionais e outras características da pasta do amido nativo e oxidado da amêndoa do caroço de manga (Mangifera indica L.), variedade Tommy Atkins. Revista do Instituto Adolfo Lutz, São Paulo, v.71, n.1, p.76-84, 2012.

OLIVEIRA, E. C. A.; SARTORI, R. H.; GARCEZ, T. B.. Compostagem. Piracicaba: Universidade de São Paulo, 2008.

PEDROSA, T. D.; FARIAS, C. A. S.; PEREIRA, R. A.; FARIAS, E. T. R.. Monitoramento dos parâmetros físico-químicos na compostagem de resíduos agroindustriais. Nativa, Sinop, v.1, n.1, p.44-48, 2013.

PEREIRA, R. A.. Compostagem em pequena escala e uso do composto como substrato na germinação de sementes de tomate (Lycopersicum esculentum). Dissertação (Mestrado em Sistemas Agroindustriais) - Universidade Federal de Campina Grande, Pombal, 2013.

PINTO, A. C. Q.. Produção e produtividade agrícola. In: ALBUQUERQUE, A. C. S.; SILVA, A. G.. Agricultura tropical: Quatro décadas de inovações tecnológicas, institucionais e políticas. Brasília: Embrapa Informação Tecnológica Brasília, 2008. p.401-409.

RIBEIRO, R. H.. Manejo da adubação nitrogenada na cultura do milho em sucessão à aveia preta em sistema plantio direto. Monografia (Bacharelado em Agronomia) Universidade Federal de Santa Catarina, Curitibanos, 2016.

RODRIGUES, L. R.; GUADAGNIN, J. P.; PORTO, M. P.. Indicações técnicas para o cultivo de milho e de sorgo no rio grande do Sul safras 2009/2010 e 2010/2011.

Veranópolis: FEPAGRO-Serra, 2009.

RODRIGUES, P. N. F.; ROLIM, M. M.; BEZERRA NETO, E.; COSTA, R. N. T.; PEDROSA, E. M. R.; OLIVEIRA, V. S.. Efeito do composto orgânico e compactação do solo no milho e nutrientes do solo. Revista Brasileira de Engenharia Agrícola e Ambiental, Campina Grande, v.15, n.8, p.788-793, 2011. DOI: http://doi.org/10.1590/S1415-43662011000800004

RONQUIM, C. C.. Conceitos de fertilidade do solo e manejo adequado para as regiões tropicais. Boletim de Pesquisa e Desenvolvimento. 8 ed. Campinas: EMBRAPA Monitoramento por Satélite, 2010.

SANTANA, C. T. C.. Comportamento de milho (Zea mays L.) e propriedades físicas do solo, no sistema plantio direto, em resposta a aplicação de fertilizante organomineral. Dissertação (Mestrado em Agronomia - Agricultura) Universidade Estadual Paulista "Júlio De Mesquita Filho", Botucatu, 2012.

SANTOS, K. O.. Utilização do amido extraído do caroço da manga (Mangifera indica L.) para aplicação como biomaterial. Monografia (Bacharelado em Química Industrial) - Universidade Estadual da Paraíba, Campina Grande, 2015.

SILVA, M. R. R.; VANZELA, L. S.; VAZQUEZ, G. H.; SANCHES, A. C.. Influência da irrigação e cobertura morta do solo sobre as características agronômicas e produtividade de milho. Irriga, Botucatu, v.1, n.1, p.170-180, 2012. Dol: http://doi.org/10.15809/irriga.2012v1n01

SILVA, R. L.; FONTES, G. C.; ROCHA-LEÃO, M. H. M.; COELHO, M. A. Z.. Extração e caracterização do amido proveniente do resíduo do processamento agroindustrial da manga (Mangifera indica L.) var. Ubá. In: CONGRESSO BRASILEIRO DE ENGENHARIA QUÍMICA, 21. Anais. Fortaleza: UFCE, 2016.

SILVA, S. M.; OLIVEIRA, L. J.; FARIA, F. P.; REIS, E. F.; CARNEIRO, M. A. C.; SILVA, S. M.. Atividade da enzima nitrato redutase em milho cultivado sob diferentes níveis de adubação nitrogenada e potássica. Ciência Rural, Santa Maria, v.41, n.11, p.1931-1937, 2011. DOI: http://doi.org/10.1590/S0103-84782011005000136

TEIXEIRA, P. C.; DONAGEMMA, G. K.; FONTANA, A.; TEIXEIRA, W. G.. Manual de métodos de análise de solo. 3 ed. Brasília: EMBRAPA, 2017.

VALENTE, B. S.; XAVIER, E. G.; MORSELLI, T. B. G. A.; JAHNKE, D. S.; BRUM JUNIOR, B.; CABRERA, B. R.; MORAES, P.; LOPES, D. C. N.. Fatores que afetam o desenvolvimento da compostagem de resíduos orgânicos. Archivos de Zootecnia, v.58, p.59-85, 2009

VIEIRA, P. A. F.; QUEIROZ, J. H.; VIEIRA, B. C.; MENDES, F. Q.; BARBOSA, A. A.; MULLER, E. S.; SANT'ANA, R. C. O.; MORAES, G. H. K.. Caracterização química do resíduo do processamento agroindustrial da manga (Mangifera indica L.) var. Ubá*. Alimentos e Nutrição, Araraquara, v.20, n.4, p.617-623, 2009

WANGEN, D. R. B.; FREITAS, I. C. V.. Compostagem doméstica: alternativa de aproveitamento de resíduos sólidos orgânicos. Revista Brasileira de Agroecologia, Dois Vizinhos, v.5, n.2, p.81-88, 2010. DOI: http://doi.org/doi.org/10.33240/rba

A CBPC - Companhia Brasileira de Produção Científica (CNPJ: 11.221.422/0001-03) detém os direitos materiais desta publicação. Os direitos referem-se à publicação do trabalho em qualquer parte do mundo, incluindo os direitos às renovações, expansões e disseminações da contribuição, bem como outros direitos subsidiários. Todos os trabalhos publicados eletronicamente poderão posteriormente ser publicados em coletâneas impressas sob coordenação da Sustenere Publishing, da Companhia Brasileira de Produção Científica e seus parceiros autorizados. Os (as) autores (as) preservam os direitos autorais, mas não têm permissão para a publicação da contribuição em outro meio, impresso ou digital, em português ou em tradução. 